07,08,09

\title{
Влияние освещения на пьезоэлектрические характеристики кварцевых резонаторов
}

\author{
() И.М. Шмытько \\ Институт физики твердого тела РАН, \\ Черноголовка, Россия \\ E-mail: shim@issp.ac.ru \\ Поступила в Редакцию 10 февраля 2021 г. \\ В окончательной редакции 10 февраля 2021 г. \\ Принята к публикации 8 марта 2021 г.
}

\begin{abstract}
Приведены результаты воздействия освещения на пьезоэлектрические характеристики кварцевых резонаторов в виде камертона, испытавших предварительную тренировку повышенным трением от внешней среды. Обнаружено значительное изменение пьезоэлектрических характеристик таких резонаторов в зависимости от интенсивности и спектра подсветки. Сделано предположение, что обнаруженное изменение характеристик резонаторов обусловлено дислокациями, образованными в резонаторе в процессе тренировки с повышенным трением внешней среды, и является проявлением хорошо известного фотопластического эффекта и его гашения.
\end{abstract}

Ключевые слова: кварцевые резонаторы, световое воздействие, фотопластический эффект, гашение фотопластического эффекта.

DOI: $10.21883 /$ FTT.2021.07.51044.025

\section{1. Введение}

В 1967 г. был открыт фотопластический эффект, заключающийся в изменении пластических характеристик полупроводниковых кристаллов под действием освещения, [1]. Впоследствии были проведены многочисленные исследования природы и кинетики этого явления на многих веществах (см., например, „Избранные труды“ академика Осипьяна, [2]), доказана общность этого явления для оптически прозрачных кристаллов и развита последовательная теория эффекта, $[3,4]$. Практический интерес к этому эффекту на какое-то время угас и сохранился только общенаучный интерес, связанный с особенностями движения электрически заряженных дислокаций в поле точечных дефектов.

В 1987 г. была опубликована наша работа „Амплитудно-чувствительные структурные изменения в кварцевых резонаторах“ [5], в которой рентгеновскими исследованиями было установлено, что после длительной резонансной тренировки дискообразных кварцевых резонаторов на рентгеновских топографических снимках резонатора регистрируются периодические и непериодические изменения контраста изображения, см. рис. 1. Эти изменения контраста предположительно обусловлены образованием дислокационных структур. Имея это в виду, а также то, что в процессе резонанса происходят значительные деформации тела резонаторов, представляло интерес изучить влияние освещения на их резонансные характеристики.

\section{2. Методика и результаты эксперимента}

Исследовались резонансные характеристики кварцевых резонаторов в виде камертона с изгибной модой колебаний. Исследования были проведены в лаборатории низких температур Мадридского автономного университета (UAM), руководимой профессором Себастьяном Виейра (Sebastian Vieira). Для этих целей использовалась установка для измерения температурной зависимости вязкости классических жидкостей с помощью кварцевых резонаторов. Технический блок такой установки показан на рис. 2.

Метод измерения вязкости заключался в следующем. На верхнюю часть плеч камертона помещалась капелька исследуемой жидкости (отмечена белой стрелкой на рис. $2, b)$. В нашем случае такой жидкостью служил $65 \%$ водный раствор глицерина. Диаметр капли составлял $\sim 1-2 \mathrm{~mm}$. После этого установка помещалась в вакуумную камеру, и измерялись температурные зависимости резонансной частоты, тока смещения и частотное изменение фазы между напряжением возбуждения и током смещения такого кварцевого резонатора. Эти характеристики, полученные без капли и с каплей, позволили вычислять искомую вязкость капли. Обычно никаких нарушений в структуру резонатора такая капля не вносила. Резонансные характеристики конкретного резонатора до и после охлаждения совпадали. Другая ситуация наблюдается, если резонатор переходит через точку замерзания водного раствора глицерина. На рис. 3 приведено температурное поведение частотных зависимостей тока смещения одного из резонаторов с такой каплей. 

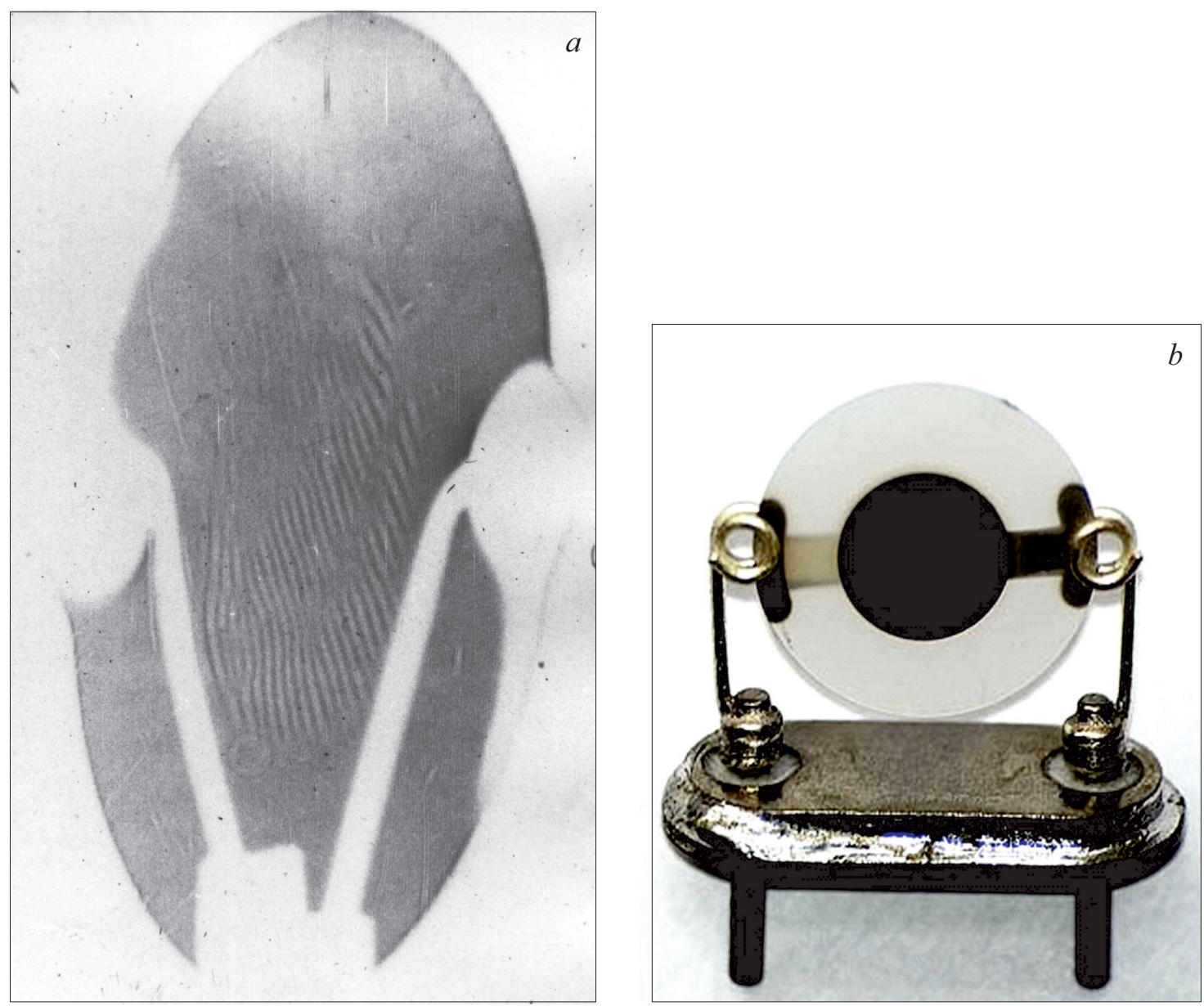

Рис. 1. Рентгеновское топографическое изображение дискообразного кварцевого резонатора после длительной тренировки в режиме резонанса - $(a)$; натуральный вид дискообразного кварцевого резонатора $-(b)$.

Основной особенностью приведенных спектров является значительное уменьшение добротности резонатора при температуре замерзания водного раствора глицерина, равной $\sim 231 \mathrm{~K}$, и восстановление этой добротности при более низких температурах. Падение добротности, на наш взгляд, связано с увеличением вязкости раствора глицерина с понижением температуры и соответствующим ростом энергетических потерь на трение. После замерзания капли резонатор меняет свою геометрию и в колебаниях участвует сам резонатор как таковой совместно с твердой каплей раствора глицерина. В этом случае уже нет тех потерь на преодоление трения, но меняется конфигурация суммарного резонатора, что и приводит к существенному сдвигу частоты резонанса, сравните кривые $4(231 \mathrm{~K})$ и $8(173 \mathrm{~K})$ на рис. 3. Отогрев такого резонатора до исходной температуры начала охлаждения приводит к понижению добротности резонатора и незначительному смещению резонансной частоты, см. рис. 4. Последнее, в свою очередь, означает появление внутри резонатора дефектов структуры (точечных дефектов, дислокаций, двойников), или изменение его формы. Для выяснения причины изменения добротности резонатора после тренировки через точку замерзания раствора глицерина были проведены два дополнительных эксперимента. Первый эксперимент заключался в сравнении резонансных характеристик „свежего“ резонатора при возбуждении в вакууме и на воздухе без предварительной низкотемпературной тренировки и без капли раствора глицерина, см. рис 5. На рисунке наглядно видно, что трение о воздух кардинально меняет и добротность, и частоту резонатора.

Второй эксперимент это измерение характеристик резонатора на воздухе, прошедшего тренировку с каплей глицерина при низких температурах, после отогрева до комнатной температуры и смыва глицерина с плеч камертона. Резонансный спектр такого резонатора показан на рис. 6 - кривая 1. Наглядно видно и заметное падение добротности резонатора и изменение частоты резонанса. Тщательный визуальный осмотр такого камертона после смыва глицерина не выявил какихлибо механических макроповреждений плеч резонатора. Поскольку геометрические характеристики при такой процедуре не изменились, уменьшение добротности резонатора можно связать только с изменением внутрен- 
ней структуры самого кварцевого камертона. К таким изменениям можно отнести, как указывалось выше, образование точечных дефектов, дислокаций, двойников. На таком резонаторе мы и провели поставленное в качестве темы исследования изучение влияния внешнего освещения на резонансные характеристики кварцевых резонаторов.
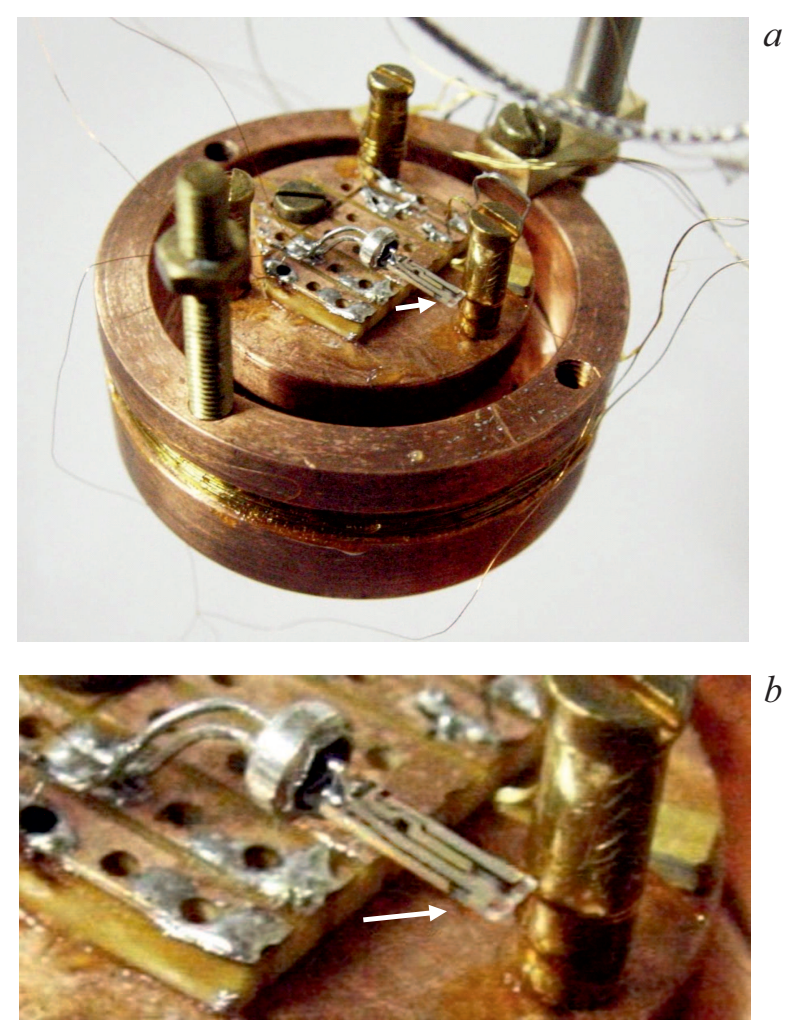

Рис. 2. Технический блок установки. $(a)-$ общий вид механического блока; $(b)-$ увеличенная часть блока, содержащего резонатор.

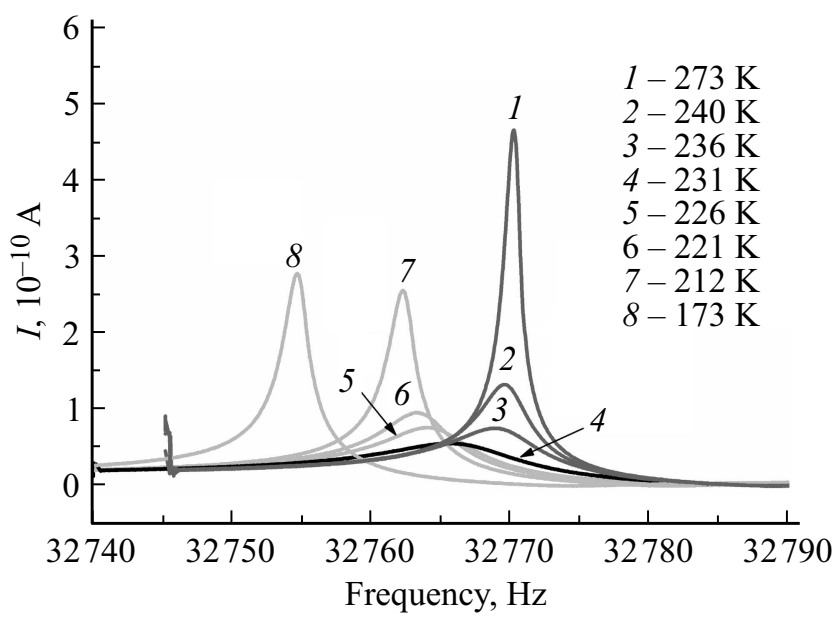

Рис. 3. Температурное изменение резонансных характеристик кварцевого резонатора в виде камертона с каплей глицерина на концах камертона.

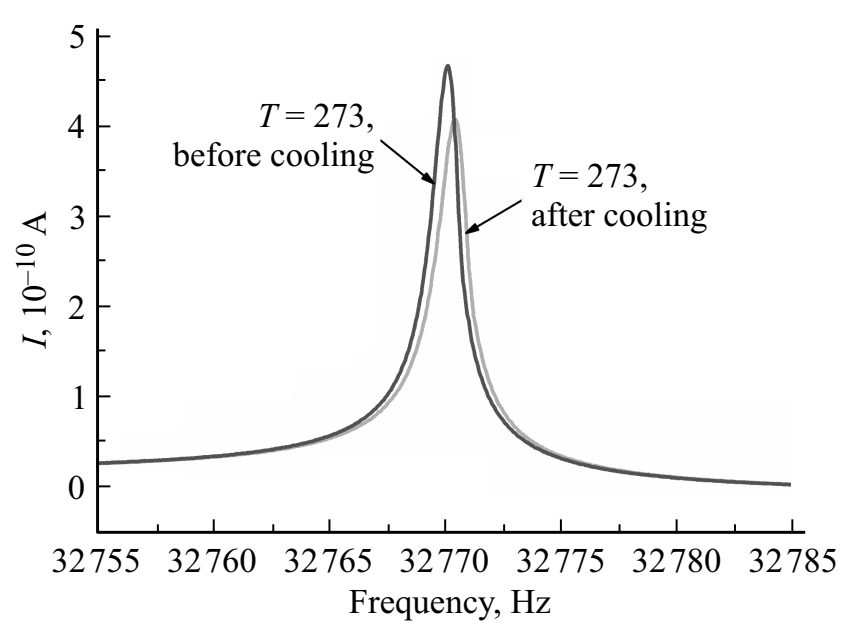

Рис. 4. Резонансные кривые кварцевого резонатора в виде камертона при $273 \mathrm{~K}$ до и после тренировки через точку замерзания глицерина.

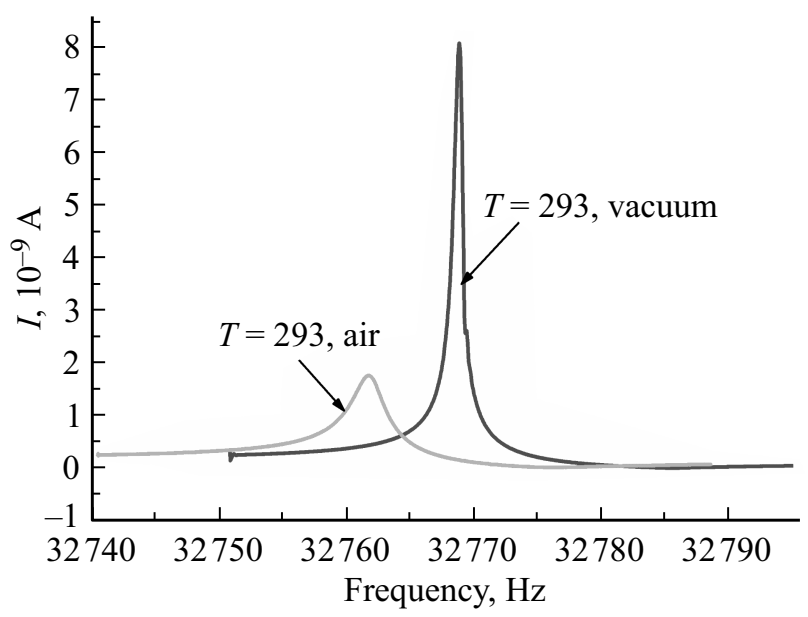

Рис. 5. Резонансные кривые кварцевого резонатора в виде камертона без капли глицерина при комнатной температуре в вакууме и на воздухе.

Было проведено два эксперимента, отличающихся уровнем освещения резонатора. В первом эксперименте для освещения использовалась обычная настольная лампа с лампочкой накаливания мощностью $60 \mathrm{~W}$, размещенная на расстоянии $\sim 70 \mathrm{~cm}$ от резонатора. Освещенность резонатора в этом случае составляла $\sim 720 \mathrm{~lx}$. Резонансный спектр при таком освещении показан на рис. 6 , кривая 2. Наглядно видно значительное уменьшение тока смещения резонатора под освещением.

Как можно объяснить такое падение тока под освещением? Воспользуемся тем фактом, что резонансные явления, наблюдаемы в электрических цепях, содержащих пьезорезонаторы, являются следствием резонансных свойств упругих колебаний, возбуждающихся в пьезоэлементе под действием приложенного к его обкладкам переменного электрического напряжения. Благодаря обратному пьезоэлектрическому эффекту, переменное 
напряжение, приложенное к обкладкам пьезоэлемента, вызывает в нем упругие колебания. Когда частота приложенного напряжения приближается к резонансной частоте упругих колебаний, их амплитуда увеличивается. Это сопровождается соответствующим увеличением упругих деформаций и вследствие прямого пьезоэффекта приводит к увеличению амплитуд колебаний электрических зарядов, создающих дополнительное напряжение на обкладках резонатора.

Чем отличаются колебания в кварцевом резонаторе с дислокациями от резонатора без дефектов кристалла. Согласно фотопластическому эффекту, описанному во введении, под освещением будет увеличиваться „жесткость“ пьезоэлемента с дислокациями. Это приведет к уменьшению амплитуды изгиба пьезоэлемента, а вследствие прямого пьезоэффекта это приведет к уменьшению суммарного напряжения на обкладках резонатора и, как следствие, к уменьшению тока в цепи.

Во втором эксперименте для проверки влияния интенсивности освещения на характеристики резонатора мы использовали добавочное освещение. Для этих целей на фоне освещенности от настольной лампы резонатор эпизодически освещался сфокусированным светом от карманного фонарика „Energizer X-Focus X215 AA“ с криптоновой лампочкой накаливания усиленной мощности, расположенного на расстоянии $\sim 15 \mathrm{~cm}$ от резонатора. Измеренная освещенность от фонарика на камертоне составляла $\sim 6670$ 1х. При этом, как и в первом случае, резонатор освещался полностью, включая соединительные участки к резонатору подводящих проводников цепи возбуждения. Результирующие спектры без освещения и суммарного освещения лампой и фонариком показаны на рис. 7. Из рисунка видно, что дополнительное эпизодическое освещение фонариком не только не приводит к дополнительному падению тока, но наоборот, приводит к почти полному гашению воздействия света от лампы.

Как можно объяснить эффект восстановления тока резонатора под действием такого мощного дополнительного освещения фонариком? Казалось бы, что наблюденный эффект можно объяснить в предположении нагрева резонатора под действием света. Однако значительное падение пьезотока под действием более слабого света от настольной лампы и его почти полный возврат (эффект гашения) при более интенсивном суммарном освещении лампой и фонариком отвергают обычный аппаратурный эффект. Эффект гашения также отвергает приконтактные явления, известные для полупроводниковых кристаллов в режиме фотовозбуждения.

Оставаясь в рамках изменения упругости материала резонатора от подвижности дислокаций и соответствующего влияния его на пьезоток, описанный выше, обратим внимание на работу Ю.А. Осипьяна, В.Ф. Петренко и И.Б. Савченко „Инфракрасное гашение фотопластического эффекта в сульфиде кадмия“ [6]. В этой работе в процессе деформации $\mathrm{CdS}$ образец с одной стороны сначала освещался основным светом в области края собственного поглощения $(\lambda=5300 \AA$,

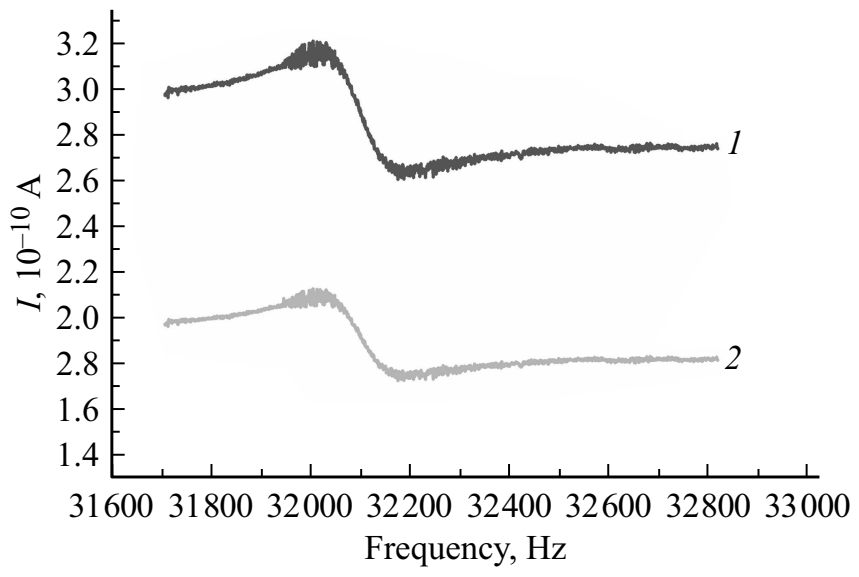

Рис. 6. Резонансные кривые на воздухе тренированного кварцевого резонатора после смыва капли глицерина с плеч камертона: (1) - спектр резонатора в темноте; (2) - спектр резонатора под действием света от настольной лампы.

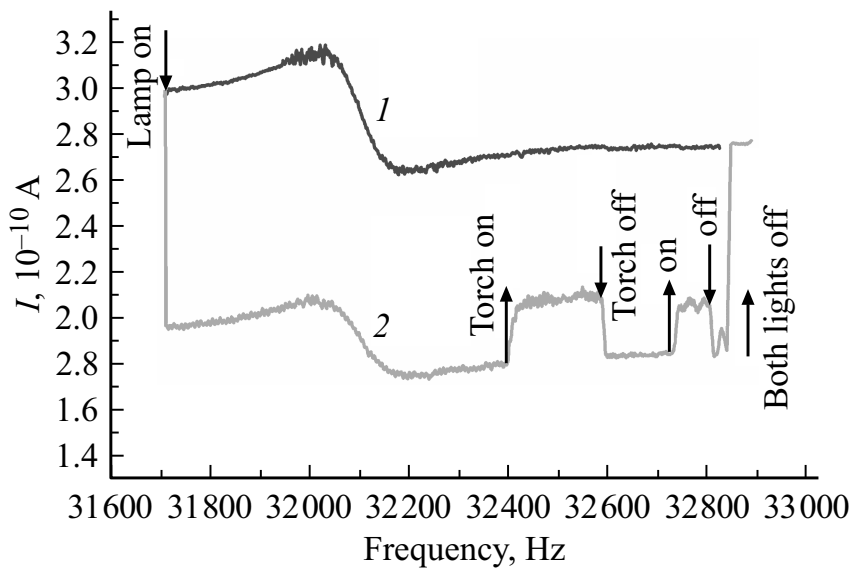

Рис. 7. Резонансные кривые на воздухе тренированного кварцевого резонатора после смыва капли глицерина с плеч камертона: (1) - спектр резонатора в темноте; (2) - спектр резонатора под действием света от настольной лампы и сфокусированного света от карманного фонарика.

$I=10^{11}-10^{13}$ photon $\left./ \mathrm{s}\right)$. Это освещение приводило к фотопластическому эффекту и сопровождалось сильным упрочнением образца. Когда упрочнение выходило на плато, образец дополнительно освещался с другой стороны ИК-светом разного спектрального состава $\left(\lambda=8000 \AA, 8700 \AA\right.$ и $9130 \AA, I=10^{13}-10^{15}$ photon $\left./ \mathrm{s}\right)$. Такая подсветка приводила к снижению напряжения течения, т. е. к разупрочнению кристалла на $\sim 20 \%$ для каждой приведенной выше длины волны ИК-света. Авторы дают следующее объяснение полученного эффекта гашения: „Под действием света, соответствующего краю собственного поглощения, образуются электроннодырочные пары с различным временем жизни электронов и дырок в свободном состоянии. Локализуясь на уровнях прилипания, дырки образуют в кристалле систему заряженных центров, взаимодействие которых 
с дислокациями определяет упрочнение кристалла при освещении (фотопластический эффект). Дополнительное освещение ИК-светом приводит к отрыву дырок от уровней прилипания и повышению эффективности рекомбинации. Этот процесс приводит к гашению ФПЭ, так как понижается концентрация локальных заряженных центров, связанных с нахождением дырок на уровнях прилипания“.

В нашем случае использовался свет широкого спектрального состава, включающем и край собственного поглощения и ИК-область. При этом измеренные спектральные распределения света от настольной лампы и фонарика оказались фактически одинаковыми, поскольку оба имеют вольфрамовую нить накала. Различие лишь в освещенности: 720 1x и $(720+6670) 1 \mathrm{x}$, соответственно. Такое сильное различие в освещенности, предположительно, и обуславливает эффект гашения при сильной подсветке. Действительно, согласно работе [6], ФПЭ в процессе деформации $\mathrm{CdS}$ осуществляется при интенсивности света собственного поглощения, равного $I=10^{11}-10^{13}$ photon/s, а для эффекта гашения требуется $I=10^{13}-10^{15}$ ИК photon/s. Это означает, что вероятность образования заряженных центров значительно выше, нежели вероятность отрыва дырок от уровней прилипания ИК-светом. Что происходит, когда освещенность маленькая. При ограниченном количестве центров прилипания из-за высокой вероятности их заполнения они будут почти все заняты, поскольку интенсивности ИК-фотонов недостаточно, чтобы их опустошить. Другая ситуация наступает, когда интенсивность суммарного светового потока очень высокая, как в нашем случае. В этом случае мощное ИК-излучение в широком интервале частот успевает опустошать заряженные центры, приводя к гашению фотопластического эффекта.

\section{3. Заключение}

Исследовано изменение пьезоэлектрических характеристик кварцевых резонаторов в виде камертона с изгибной модой колебаний, испытавших сначала предварительную тренировку повышенным трением от внешней среды, а затем воздействие света разного спектрального состава и разной интенсивности. Воздействие внешнего трения приводило к значительному падению добротности резонатора, резонансной частоты и полуширины резонансной кривой. Последующее освещение такого резонатора от лампы накаливания приводило к изменению пьезоэлектрических характеристик резонатора, зависящему от интенсивности освещения резонатора. Так освещение от настольной лампы, размещенной на расстоянии $70 \mathrm{~cm}$ от резонатора и обеспечивающей среднюю освещенность камертона $\sim 720 \mathrm{~lx}$ приводило к падению тока смещения резонатора приблизительно на 33\%. Дополнительные эпизодические освещения высокой интенсивности от карманного фонарика „Energizer X-Focus X215 AA“ с криптоновой лампочкой накаливания усиленной мощности, расположенного на расстоянии $\sim 15 \mathrm{~cm}$ от резонатора и обеспечивающей среднюю освещенность камертона $\sim 6670$ lx, приводило к практическому восстановлению тока смещения резонатора - эффект гашения. Сделано предположение, что обнаруженный эффект изменения резонансных характеристик кварцевых резонаторов в виде камертона с изгибной модой колебаний под действием освещения является проявлением хорошо известного фотопластического эффекта и его гашения в зависимости от частоты и интенсивности воздействующего света.

\section{Благодарности}

Автор выражает искреннюю благодарность проф. Себастьяну Виейра (Sebastian Vieira) и Росио де Гранде Равло (Rocio de Grande Pavlo) из лаборатории низких температур Мадридского автономного университета за предоставленную возможность проведения настоящих исследований.

\section{Финансирование работы}

Работа выполнена в рамках госзадания ИФТТ РАН.

\section{Конфликт интересов}

Автор заявляет, что у него нет конфликта интересов.

\section{Список литературы}

[1] Ю.А. Осипьян, И.Б. Савченко. Письма в ЖЭТФ 7, 130 (1968).

[2] Ю.А. Осипьян. Избр. труды. Борей, М. (2012). 480 с.

[3] Ю.А. Осипьян, В.Ф. Петренко. ЖЭТФ 63, 1735 (1972). [Yu.A. Osip'yan, V.F. Petrenko. Sov. Phys. JETF 36, 916 (1973)].

[4] Р.А. Варданян, В.Я. Кравченко, Ю.А. Осипьян. Письма в ЖЭТФ 40, 248 (1984).

[5] В.В. Боровиков, Р.А. Диланян, И.М. Шмытько. ЖТФ 57, 540 (1987).

[6] Ю.А. Осипьян, В.Ф. Петренко, И.Б. Савченко. Письма в ЖЭТФ 13, 622 (1971).

Редактор Ю.Э. Китаев 